\title{
A cinematographic fence and ornamental oars Experiencing the sublime in structures of urban public space
}

approach the theme of the sublime experience in public urban space from the point of view of a visual artist and from one of a person walking through the city. In this essay a concrete sublime experience in public urban space is analysed through an experimental artistic intervention. In this way knowledge is gathered about the relationship between public urban space and its users. I engage in a dialogue with the ancient understanding of the sublime as an effect of elevated, performed language. Features of this rhetoric are adapted on to the visual appearance of public urban space in order to reveal situations that evoke sublime experiences.

OUR UNDERSTANDing OF THE AEsthetic and philosophical concept of the sublime has changed through time. In the twenty-first century sublime thought has been connected to digital technology and technological artistic productions such as new media and telecommunication arts. In the twentieth century, the concept of the sublime was related to metropolitan and industrial developments. Before that in the eighteenth century and in the Romantic era, the sublime was an expression of the experience of nature filling us with awe, wonder, or even horror, as for example in paintings depicting dramatic landscapes such as the Alps or a stormy sea. Philosophers like Edmund Burke (1729-97), Immanuel Kant (1724-1804), Arthur Schopenhauer (1788-1860) or Jean-François Lyotard (1924-98) formed our understanding of the concept of the sublime.

Their interpretations of the sublime share, to different extents, the same aim: that is, to emphasize the limited nature of the self. The self is confronted with an overwhelming, sublime greatness existing outside itself (Morlay 2010: 15). The focus in these definitions of the sublime is on an evocation of an experience of uncertainty and fear, or even pain and horror. Connected to artistic expression in drama or in paintings such fear may be followed by pleasure in the form of a catharsis (upon realizing it's only art, not real). On the other hand, the sublime experience of fear, pain or sheer terror can be used as a tool to evoke the need for heroes and salvation.

For example an act of violence committed in public space renders a random place on earth temporarily the focus of (media) interest. A place and its happenings are suddenly and unexpectedly elevated as a consequence terrifying events occuring there. Through information technology and new media the images of the event are spread in an instant around the globe. The images depicting the event often contain the staging of heroic actions: for example an image of New York firefighters, following the events of 9/11, raising a USA flag at ground zero. This image becomes an aestheticized memory in the form of a heroic memorial (Becker 2013: 166)

I will not pursue here a discussion of the sublime in connection to terror and violence. These interpretations of the sublime are not the focus of this essay. Instead, I would like to turn back (or rather forward) to an interpretation of the sublime where the kind of feelings involved are not specified, apart from being extraordinary.

\section{Rhetoric and the sublime}

In the ancient sources of the sublime the notion was closely connected to language, writing and rhetoric. I refer here to Longinus' On the Sublime (Peri hypsous), a treatise on good writing in which the presumed 
author gives concrete advice on how to compose a rhetorically good speech. He states:

The effect of elevated language upon an audience is not persuasion but transport. At every time and in every way imposing speech, with the spell it throws over us, prevails over that which aims at persuasion and gratification.

(Roberts 1899: I, 4) ${ }^{1}$

For Longinus grandeur or greatness is virtually synonymous with the sublime. The sublime manifests itself through the audience's total immersion into the subject matter of the speech and in an insightful identification with it:

For by some innate power the true sublime uplifts our souls; we are filled with a proud exaltation and a sense of vaunting joy; just as though we had ourselves produced what we had heard. (Murray and Dorsch 2000: 120)

The rhetoric Longinus is referring to is closely connected to an actual speech conducted in public space. Public speech always has a relationship not only to a live audience but also to a concrete public space, to the place where the speech is given. It is in that sense that I examine public urban space: I adapt rhetorical devices ${ }^{2}$ by means of visual art into the experience of events in public urban space.

\section{Talking aloud in public space}

I understand rhetoric, as mentioned above, quite literally as 'talking aloud in a public space'.

1 I use here the translation from 1899 because of the pertinent use of the expression 'transport'. The same passage in a more recent translation (Murray and Dorsch 2000: 114): 'For the effect of elevated language is not to persuade the hearers, but to amaze them; and at all times, and in every way, what transports us with wonder is more telling than what merely persuades or gratifies us.'

2 To reach elevation in speech, rhetorical devices such as repetition, asydeton (omitting conjunctions between words, phrases, or clauses), hyperbaton (inversion in the arrangement of common words) and irony have to be used in an appropriate way. Improving the use of these, among other rhetorical devices, improves and 'elevates' the impact of the speech on the audience and renders it sublime.
While talking aloud, sound waves travel through the space and bounce off the limits of the space such as walls, the floor and furniture. The human voice is an efficient way to explore the relationship between an individual human being and the architectural space around him/her. For example, when riding a bicycle through a motorway underpass I used to shout and listen to the echo coming back. The louder I shouted, the more impressive was the experience of the space that had just been filled with my sound. For some reason, it was in the moment right after it - when the echo of my voice had stopped - that the experience of the volume of the space was the most powerful. At this instant, I had a strong, uplifting feeling of myself passing through the tunnel.

\section{A surprising gift}

The situation of me going through a tunnel on a bike and the uplifting feeling it generated is a sublime experience that I evoked myself (with my thoughts, voice and feelings) in relation to a concrete situation in public urban space. The sublime experience in this situation is a subjective conception, something that takes place in the mind. It is a subjective conception going beyond our capacity to completely understand or control our experiences (Kant 1973: 106).

The projection of the self into a concrete, urban situation caused a sudden, unexpected and overwhelming yet uplifting feeling in which the sublime happened as a gift and surprise, not as a reward for heroic action or as a climax after enduring pain. I myself, together with the concrete situation in urban space created an uplifting feeling in the form of a sudden, surprising experience without involving oppressive feelings of fear or terror.

This uplifting feeling is connected to a high degree of awareness of the self in the situation in question (Morlay 2010: 14). By this I am referring to an extraordinary feeling of what is happening right now in this situation.

\section{The sublime in the urban now}

A concrete situation in public urban space is always a place of action that involves not only its present and former users but also a long chain of actions of different people that contributed to its present state. By that I mean all objects in public urban space represent former actions by someone; actions linked to 
their design, production and so forth. These actions have taken place at different times, even in different centuries. The urban surroundings confront the individual with the direct or indirect now of others in person, or through the objects of its infrastructure (like buildings, walls, streets, bus stop shelters). This is why urban public space affords the possibility of putting the self into a perspective in a very different way than, for example, when walking in nature. Each situation in public urban space is a social engagement per se, even if you are there all by yourself.

The artist Olafur Eliasson talks about the interactions of humans regarding their experience of the now. He sees the now as an entity which is extended in time and space, stating 'Your now is my surroundings and vice versa' (Eliasson 2010: 123). This means that every object in public urban space is connected to many nows of different people interacting with them and with each other (from their design to production and daily use).

I would regard public urban space as mainly consisting of these interactions. However, we have quite a narrow awareness of these interactions and of how big our influence on public urban space actually could be. Public urban space is not just created in a hierarchical act and then used. Instead we create it ourselves by interacting with its infrastructure and, through that, by interacting with other people's actions in different layers of time. The conceptualisation and manifestation into a work of art of these interactions can evoke a form of the sublime (Eerikäinen 2016: 178-202). For me, working in and with public space is also a political act, contributing to a city's development in a way that questions hierarchical structures in both physical space and the organisation of society.

In the following account, I would like to demonstrate another example of a sublime experience in public urban space. It includes the interpretation of a sublime experience through the rhetoric of an artistic intervention.

\section{Walking along a fence}

A street called Aittaluodonkatu near the centre of Pori on the west coast of Finland is cut off abruptly by an approximately 30-metre long and two-metre high wooden fence. The fence separates a housing area with long, low three-storey buildings from an industrial area including a cardboard factory and an electricity plant. The fence is built in a robust way, the raw boards are beautifully aged and they are covered with a patina in many shades of grey. On top of the fence, on the side of the fence facing the industrial area, there are two horizontally aligned lines of barbed wire. They are not visible from the other side of the fence (Fig. 1).

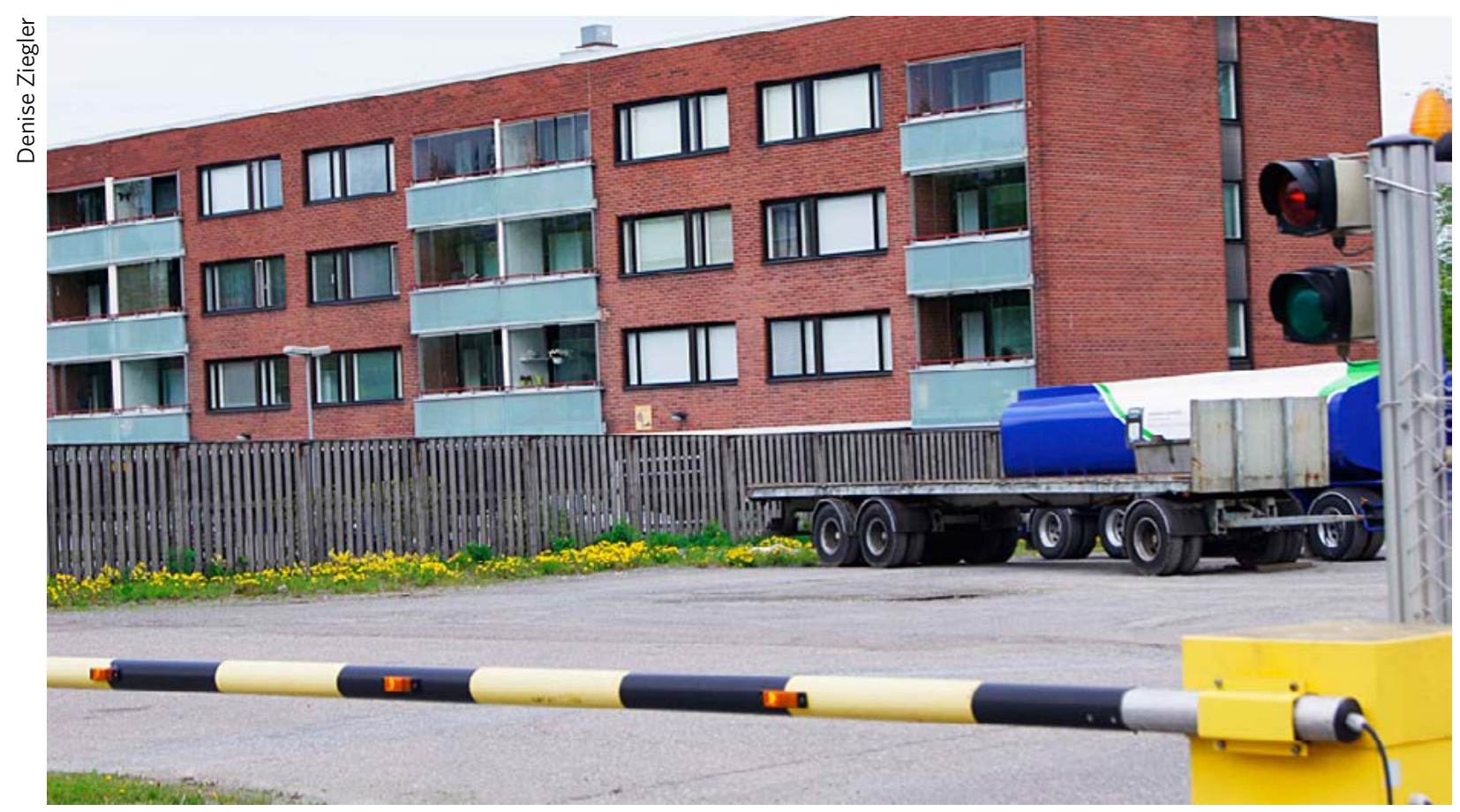

Fig. 1. A wooden fence separates an industrial area from a housing area. Research photograph for the experimental artistic intervention Oars for a Fence, 2016, Aittaluoto, Pori. 

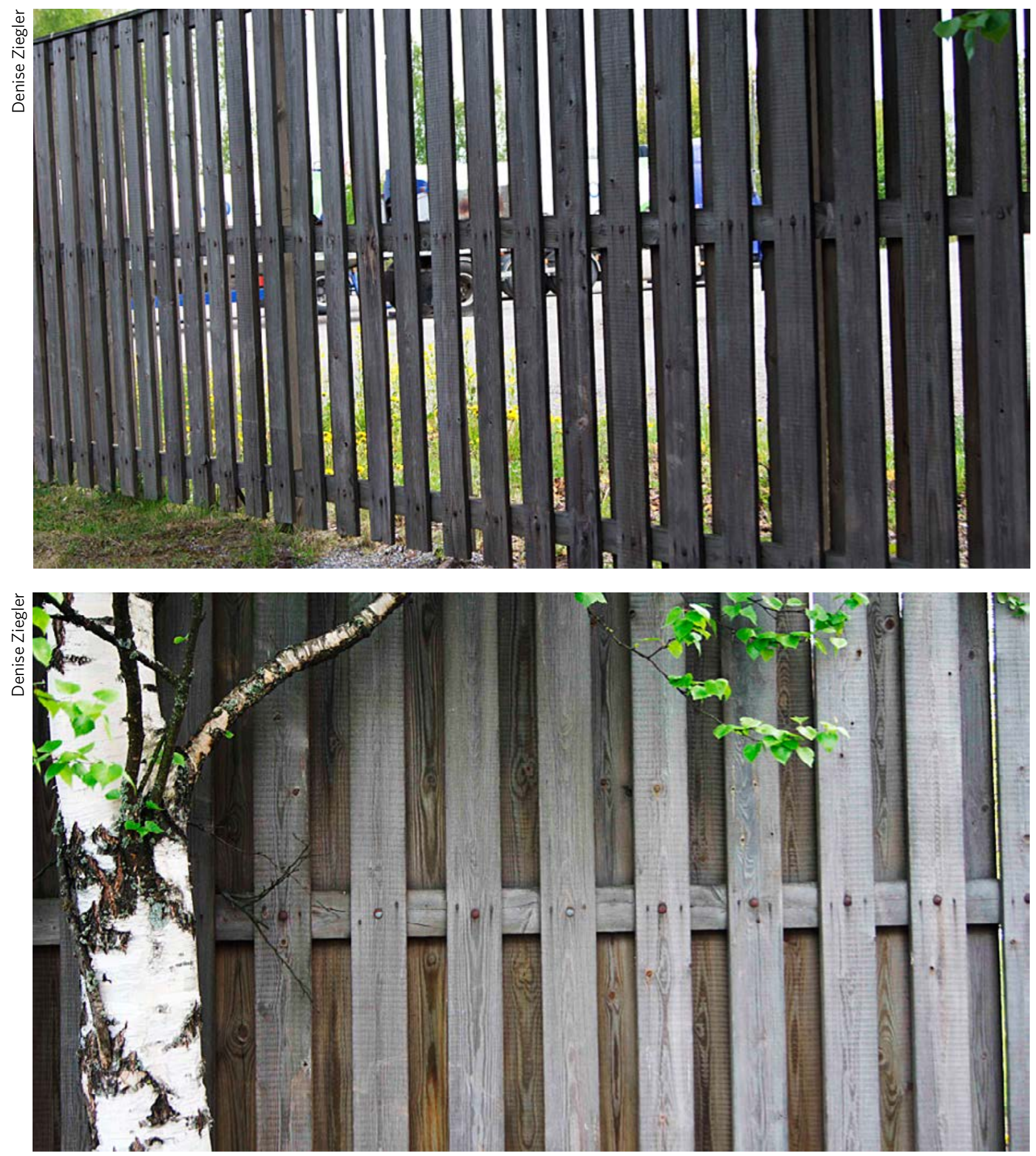

Fig. 2 (top). When viewing a two-sided fence from a moving vantage point, the view on the other side of the fence has the appearance of the movements of a film. Research photograph for the experimental artistic intervention Oars for $a$ Fence, 2016, Aittaluoto, Pori.

Fig. 3 (bottom). When the two-sided fence is viewed directly en face from a 90 degree angle, the interspersed upright boards completely prevent a view of the other side. Research photograph for the experimental artistic intervention Oars for a Fence, 2016, Aittaluoto, Pori. 


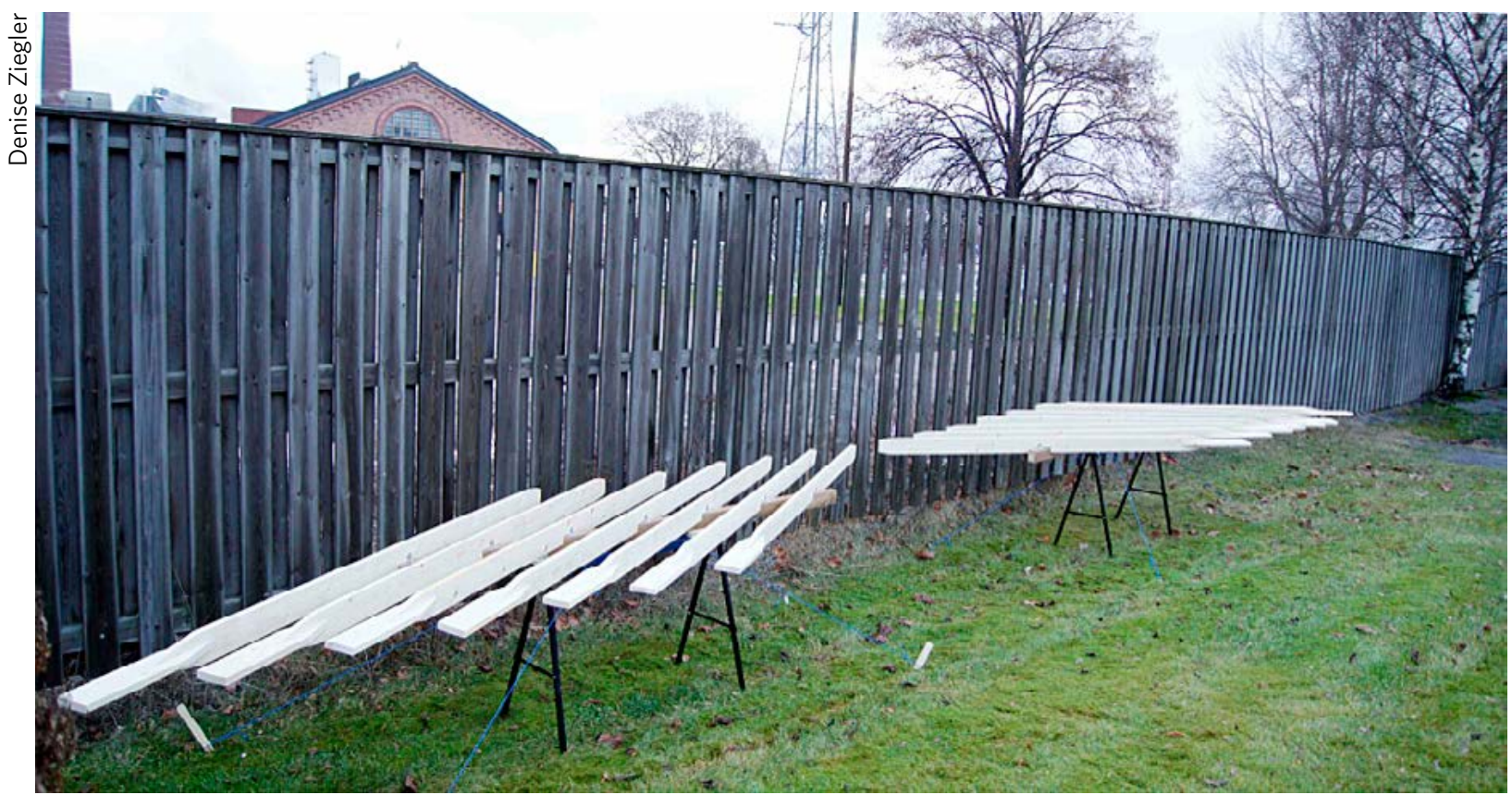

Fig. 4. Denise Ziegler, Oars for a Fence (2016), experimental artistic intervention, Aittaluoto, Pori. A temporary work in public space: next to a fence two sets of stylised oars are placed pointing in two opposite directions, according to the two positions of oars between a rowing movement.

Previously, there was a passageway here to the cardboard factory, and there were even railway tracks passing through the street to the factory. In the $1970 \mathrm{~s}$ the railway tracks were dismantled and the factory area was separated from a newly-built housing area with a light chain-link fence. This fence has later been replaced by the heavy wooden fence that is there today. The fence was built most probably by the Rosenlew company; at present the property is owned by UPM Biofore.

The type of fence in question is a so-called 'twosided' fence, with cross-members placed horizontally at three levels (bottom, middle and top) and attached on both sides to upright members with nails and bolts. The upright boards are interspersed to leave wide gaps between them (Fig. 2).

When viewing the fence from a moving vantage point, that is to say walking next to it with the gaze turned 45 degrees forward or 45 degrees behind, one can see through it to the other side. The view on the other side of the fence has the appearance of an illusion, or the movements of a film. The upright boards and their gaps namely alternate to block and reveal the view on the other side. The upright boards and their gaps function like an analogue film projector, in which the rapid alternation of the shutter animates quickly changing images into a film. That is why I call this type of fence a cinematographic fence. The phenomenon of the cinematographic fence is a paradox in which reality (the real events on the other side of the fence) appears as an illusion. In this paradox, illusion and reality are inter-exchanged. Usually we try to make an illusion look real, whereas here reality is perceived to be like an illusion.

While walking along the fence, I am suddenly involved in questions of perception, reality, illusion and my 'self'. The situation has captured my attention. I want to know more about it.

\section{Anticipation and recall}

When the fence is viewed directly en face from a 90-degree angle, the interspersed upright boards completely prevent a view of the other side. This can be interpreted so that the fence gives someone walking next to it two opportunities to observe what is happening on the other side: to anticipate (to observe what lies ahead) or to recall (to observe what one has left behind) (Fig. 3).

The double-sided fence offers the opportunity to reflect on the concept of now from the perspective of anticipating and recalling.

As in negative theology (apophatic theology; approaching God by describing what he is not), in 


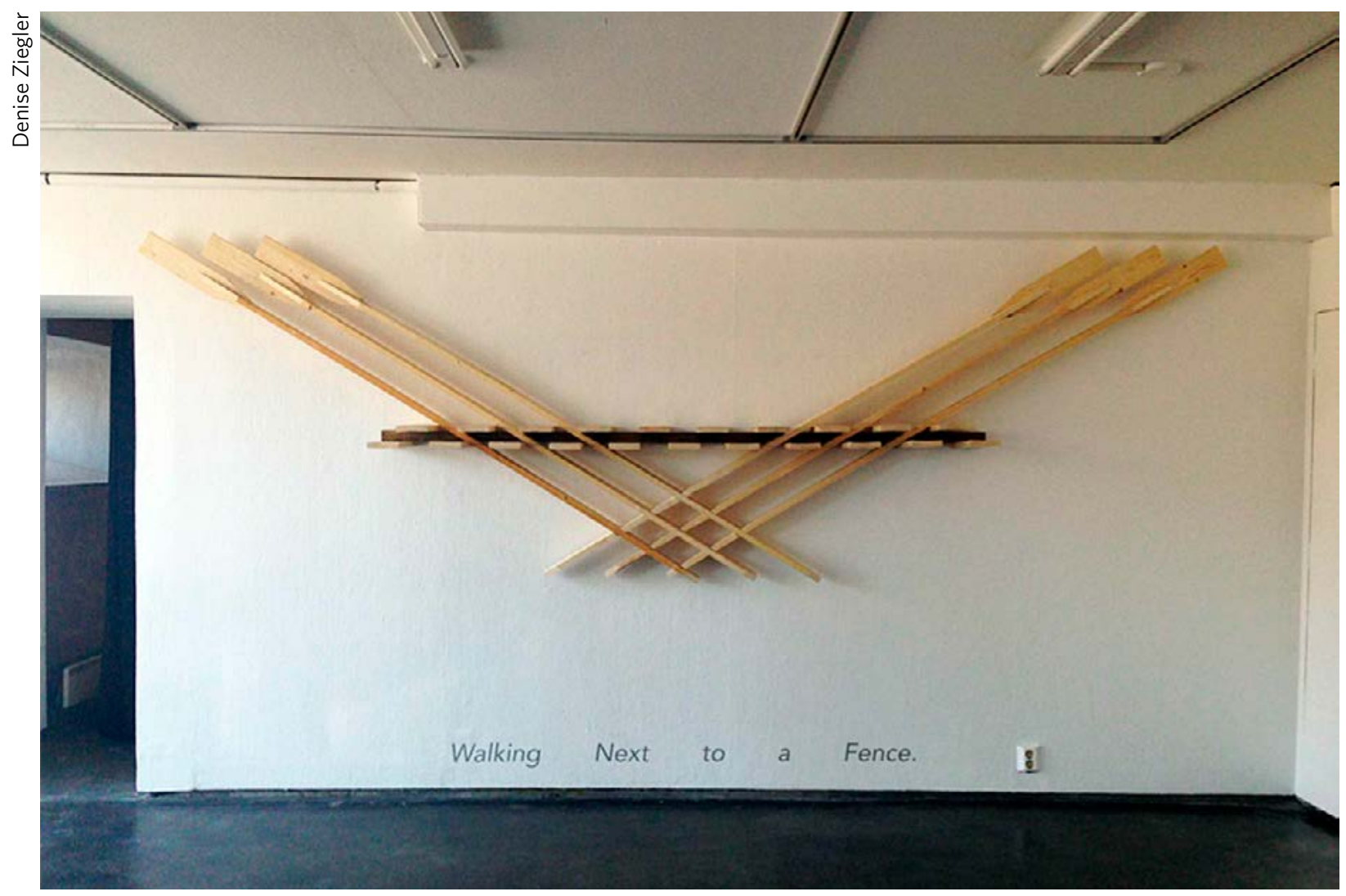

Fig. 5. Denise Ziegler, Walking Next to a Fence (2016), wood and text, approx. $245 \mathrm{~cm}$ x $450 \mathrm{~cm}$. A bird's-eye view of a twosided fence and stylised oars. Titanik Gallery, Turku, Finland.

the situation with the double-sided fence the now is defined by what it is not: the only things visible are what will be and what has been an instant ago.

The person thus walking next to the fence will not have the present moment. Just as there will neither be any actual moving image. What we call the moving image is an illusion of perception, a trick playing on the limitations of our visual apparatus.

Walking along the fence, I find a model for the relationship between the self and time and space. Instead of emphasizing the self in the now and yet (as is so fashionable to do at present) the fence walker looks forward and backwards in order to orientate himself, that is to say, in order to see what is happening on the other side of the fence.

What lies in between looking forward and looking back is an imagined V-shaped 'blind' area of nonvisibility opening up on the other side of the fence. This imagined $\mathrm{V}$ shape proceeds with the fence walker on the other side of the fence. The experience of this V-shaped 'non-visibility' might be called the 'negative now'. It defines where the fence walker is at the current state and describes his or her movements.
The interaction between the fence and the walker gives the viewer an extraordinary, surprising feeling of reality.

In this kind of sublimity, no threat to the self is involved. On the contrary, while experiencing it, the user of public space is not even separated from, say, daily routines. The place where this extraordinary feeling has occurred can be revisited and it might be used as a kind of a 'pit stop' for the recreation of the self.

These described events are the starting point for an experimental artistic intervention conducted in order to manifest the extraordinary experience of the 'negative now' experienced while walking along a fence. I reconstructed the experience in the form of an artistic intervention in public space and eventually in the form of a sculpture for an exhibition space. Artistic research allows me to think in an associative way and to interpret the act of walking along and looking through the fence in a work of art. 


\section{Oars for a Fence: an intervention in public urban space}

If the gazes reaching through the gaps in the fence were solid matter - for example the boughs of trees, or objects like oars - the perceptions of a person walking next to the fence could be manifested by means of sculpture. By this I mean that the experiential perception would be given form and materiality (Fig 4).

The experimental intervention on-site was entitled: Oars for a Fence (Ziegler 2016a). Next to the fence I placed two sets of stylised oars pointing in two opposite directions, according to the two positions of oars in a rowing movement. I interpret looking ahead and looking back through the fence through these two different positions of sets of oars: one set of seven parallel oars being oblique to the horizontal beam and pointing left (or forward) and one similar set of oars pointing right (or backwards). Marking these two positions of the movement of rowing (before and after one pull on the handles), I wanted to explore what happens in the space left between the two sets of oars.

In connection with the conference Art Approaching Science and Religion I was part of a group exhibition entitled 'Ornament and Beauty' at the Titanik Gallery in Turku 2016 (Ziegler 2016b). My contribution to the show was to sum up the findings of the experimental intervention in the form of an ornamental work on the wall of the gallery.

\section{Walking Next to a Fence}

Mounted on the wall of the exhibition space is an imaginary situation constructed of rough-cut boards, showing a bird's-eye view of a two-sided fence and stylised oars. The piece has experimental and ornamental features (Fig. 5).

The conceptualised experience of walking along a fence is an expression of the sublime. It gives exceeded imagination form and material and at the same time it condenses the experience of the now, in this case the negative now. Sublime experiences of the (negative) now in connection with urban surroundings can be a key to understanding the self and its presence as an essential part of constantly moving surroundings in urban space.

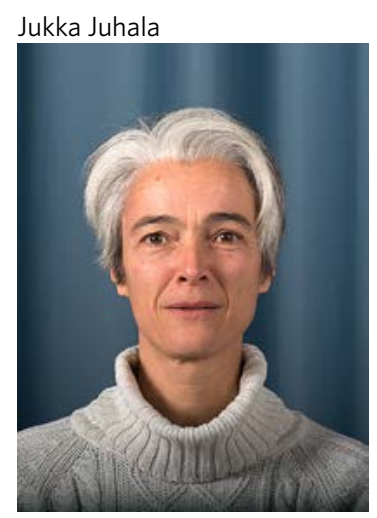

DFA Denise Ziegler is a Helsinki based artist and researcher of public space. She received her doctoral degree at the Academy of Fine Arts in Helsinki. She is currently a postdoctoral researcher at PUPA (Pori Urban Platform) at Aalto University, Finland. In her recent project she has been developing a new kind of understanding of public urban space through experimental artistic interventions.

\section{References}

Becker, Anne, 2013. 9/11 als Bildereigniss (transcript image, Bielefeld)

Eerikäinen, Hannu, 2016. 'Conceptuality as a form of the sublime: a theoretical Gedankenexperiment' in Moscow Conceptualism: Erosion and After, ed. Kimmo Sarje (The Academy of Fine Arts at the University of the Arts Helsinki), pp. 178-208

Eliasson, Olafur, 2010. 'The weather forecast and now' in The Sublime: Documents of Contemporary Art, ed. Simon Morley (London, Whitechapel Gallery Ventures Limited), pp. 123-4

Kant, Immanuel, 1973 (1790). Critique of Judgement, tr. J. J. Meredith (Oxford and New York, Oxford University Press)

Morlay, Simon (ed.), 2010. The Sublime: Documents of Contemporary Art, (London, Whitechapel Gallery Ventures Limited)

Murray, Penelope, and T. S. Dorsch (tr.), 200o. Longinus, 'On the Sublime' in Classical Literary Criticism (London, Penguin Books)

Roberts, W. Rhys (tr.), 1899. On the Sublime, by Longinus (Cambridge University Press), <http:// classicpersuasion.org/pw/longinus/index.htm $>$ (accessed 23.5.2016)

Tudeer, O. E. (tr.), 1918. Korkeasta tyylistä (Peri hypsus), by Longinus (Helsinki, Otava)

Ziegler, Denise, 2016a. Oars for a Fence, temporary intervention in public space, Aittaluodonkatu, Pori, 1.12.2015-16.3.2016

-2016b. 'Walking Next to a Fence' in Ornament and Beauty, ed. AmosLAB (Turku, Titanik Gallery) 